McKellar, A. E., S. E. Simpson, and S. Wilson. 2021. Abundance, population trends, and negative associations with lake water levels for six colonial waterbird species over five decades in southern Manitoba. Avian Conservation and Ecology 16(1):7. https://doi.org/10.5751/ACE-01789-160107 Copyright (C) 2021 by the author(s). Published here under license by the Resilience Alliance.

Research Paper

\title{
Abundance, population trends, and negative associations with lake water levels for six colonial waterbird species over five decades in southern Manitoba
}

\author{
Ann E. McKellar ${ }^{1}$ (D), Steven E. Simpson ${ }^{2}$ and Scott Wilson ${ }^{3,4}$ \\ ${ }^{1}$ Canadian Wildlife Service, Environment and Climate Change Canada, ${ }^{2}$ Ministry of Forests, Lands, Natural Resource Operations \\ and Rural Development, Government of British Columbia, Canada, ${ }^{3}$ Wildlife Research Division, Environment and Climate Change \\ Canada, ${ }^{4}$ Department of Forest and Conservation Sciences, University of British Columbia, Canada
}

\begin{abstract}
Management of colonial waterbirds at regional, national, and continental scales requires up-to-date monitoring information on breeding locations, population sizes, and trends. The large lakes of southern Manitoba, Canada (Winnipeg, Winnipegosis, and Manitoba), and the inter-lake region host nationally and continentally significant populations of colonial waterbirds, but the area has been surveyed only irregularly in the past. We conducted surveys in 2017 to produce updated information on population abundance and trends for the six most abundant species breeding on the lakes: Ring-billed Gull (Larus delawarensis), Herring Gull (Larus argentatus), Caspian Tern (Hydroprogne caspia), Common Tern (Sterna hirundo), Double-crested Cormorant (Phalacrocorax auritus), and American White Pelican (Pelecanus erythrorhynchos). We also examined the relationship between lake water levels and breeding pair abundance on Lake Winnipegosis. All species but American White Pelicans showed declines in recent years, and most notably populations of Caspian Tern and Common Tern were as low as or only just above 1970s levels, respectively. Higher water levels were associated with fewer breeding pairs of colonial waterbirds. The effects of water regulation in this region on colonial waterbirds and their habitat warrants further research, as does the degree to which the species use smaller lakes spread throughout the western boreal forest for breeding, especially during high water years on the lakes in southern Manitoba.
\end{abstract}

\section{Abondance, tendance des populations et associations négatives avec les niveaux d'eau des lacs pour six espèces d'oiseaux aquatiques coloniaux sur cinq décennies dans le sud du Manitoba}

RÉSUMÉ. La gestion des oiseaux aquatiques coloniaux à l'échelle régionale, nationale et continentale requièrent des données de suivi actualisées sur les sites de nidification, la taille des populations et les tendances. Les grands lacs du sud du Manitoba (Winnipeg, Winnipegosis et Manitoba), au Canada, et la région interlacs accueillent des populations d'oiseaux aquatiques coloniaux importantes à l'échelle nationale et continentale, mais cette région n'a fait l'objet de suivis que de façon irrégulière par le passé. Nous avons réalisé des inventaires en 2017 afin de mettre à jour les données d'abondance et de tendance des populations des six espèces les plus abondantes nichant sur les lacs : le Goéland à bec cerclé (Larus delawarensis), le Goéland argenté (Larus argentatus), la Sterne caspienne (Hydroprogne caspia), la Sterne pierregarin (Sterna hirundo), le Cormoran à aigrettes (Phalacrocorax auritus) et le Pélican d'Amérique (Pelecanus erythrorhynchos). Nous avons également examiné la relation entre le niveau d'eau et l'abondance des couples nicheurs sur le lac Winnipegosis. Toutes les espèces, sauf le pélican, ont connu une diminution d'effectifs ces dernières années, tout particulièrement les Sternes caspiennes et les Sternes pierregarin, dont les niveaux respectifs de population étaient aussi bas ou à peine supérieurs à ceux des années 1970, respectivement. Des niveaux d'eau plus élevés ont été associés à un nombre plus faible de couples nicheurs d'oiseaux aquatiques coloniaux. Les effets de la régulation de l'eau sur les oiseaux aquatiques coloniaux et leurs habitats dans cette région méritent de plus amples recherches, tout comme dans quelle mesure les espèces utilisent les petits lacs répartis dans la forêt boréale de l'Ouest pour nicher, en particulier pendant les années où les niveaux d'eau des lacs du sud du Manitoba sont élevés.

Key Words: American White Pelican; Caspian Tern; Colonial waterbird; Common Tern; Double-crested Cormorant; Herring Gull; Lake Winnipeg; population census; Manitoba; Ring-billed Gull

\section{INTRODUCTION}

Many waterbirds are declining globally, with habitat loss and degradation, water regulation, agricultural intensification, and human disturbance identified as key threats (Kushlan et al. 2002, Amano et al. 2017). In Canada, some species of waterbirds have increased since the 1970s in part due to reduction in the use of pollutants such as DDT, but others continue to decline (NABCI
Canada 2019). While these patterns provide an indication of overall long-term trends, waterbirds as a group are difficult to survey. Many species breed colonially, often at remote sites, and as such they are poorly covered by standardized monitoring programs (e.g., $\sim 1 / 3$ of species have no or poor-quality data; NABCI Canada 2019). As a result, we often have little certainty as to whether populations are increasing, decreasing, or stable, 
and total abundance often remains unknown. Management of these species at regional, national, and continental scales requires updated monitoring information on breeding locations and population sizes and trends.

Colonial waterbirds often display dynamic site occupancy (e.g., frequent inter-annual colonization and extinction events), which may be related to various biotic and abiotic factors, although direct causes are often poorly understood and species-specific (Erwin et al. 1998, Wyman et al. 2014). In particular, inter-annual water level fluctuations are known to influence colonial waterbird presence and reproductive success. For example, colony sites more at risk of flooding are less likely to persist in the Great Lakes (Wyman et al. 2014), and high water levels can cause flooding of islands and reduce nesting habitat availability. These events might cause individuals to disperse to other sites in high water years or forego breeding altogether. Thus, changes in abundance at a colony over time may be due to a true demographic change in abundance or movement, which presents an additional challenge for how to interpret monitoring data. While high water events can impact reproductive success and present a challenge for surveys, occasional flooding is potentially beneficial for long-term suitability of colonies for breeding because it can prevent excessive growth of vegetation on islands and maintain more sparsely vegetated rocky or sandy substrate preferred for nesting (Evans 1972). In some cases high water levels may also have a positive effect on colony presence by creating suitable nesting islands on land previously connected to the mainland (Moreno-Matiella and Anderson 2005).

Southern Manitoba supports nationally and continentally significant populations of several species of colonial waterbirds (Koonz and Rakowski 1985). In particular, Lake Winnipeg, Lake Winnipegosis, Lake Manitoba, and the associated inter-lake region host some of the largest North American inland populations of Ring-billed Gull (Larus delawarensis), Herring Gull (Larus argentatus), Caspian Tern (Hydroprogne caspia), Common Tern (Sterna hirundo), Double-crested Cormorant (Phalacrocorax auritus), and American White Pelican (Pelecanus erythrorhynchos) outside of the Great Lakes Region (Weseloh et al. 2002, Morris et al. 2010, Cotter et al. 2012, Wilson et al. 2014). Due to the remoteness of this region and the vast area of most of the lakes, dedicated surveys are required to obtain abundance and trend information for these species. Southern Manitoba is sensitive to extreme flooding events, with at least 12 events recorded in the Assiniboine River basin since the early 1900s, including the flood of 2011 (Brimelow et al. 2014). In addition, water levels on Lake Manitoba and Lake Winnipeg have been regulated by Manitoba Hydro since 1961 and 1976, respectively, and Lake Winnipegosis drains exclusively into Lake Manitoba. Despite their importance, there have been no regularly occurring waterbird surveys of these lakes, and prior to 2012, the lakes had not been jointly surveyed since 1979 (Koonz and Rakowski 1985, Wilson et al. 2014). In contrast, the Great Lakes Region is surveyed every 10 years as part of a joint US-Canada Great Lakes Colonial Waterbird Census (Weseloh et al. 2002, Morris et al. 2010, 2011). In 2012, the Canadian Wildlife Service conducted a joint survey of Lakes Winnipeg, Winnipegosis, and Manitoba and the inter-lake region, and made the recommendation to repeat the survey at regular intervals to obtain updated population trends (Wilson et al. 2014). As such, the area was re-surveyed five years later in 2017, which is the main focus of this study.

In 2011, the Canadian Wildlife Service conducted a partial survey of some colony sites on Lakes Winnipeg and Winnipegosis, and a handful of smaller lakes in the inter-lake region. However, due to extremely high water levels and flooding of nesting islands that year, the full survey was deferred to 2012 (Wilson et al. 2014). Based on the 2012 survey results in comparison to earlier data, all six target species had apparently increased in abundance since 1979, but Caspian Terns, Common Terns, and Double-crested Cormorants appeared to have decreased in abundance since the early 1990s (Wilson et al. 2014). These population fluctuations, alongside the results from the partial 2011 survey during a flood year, prompted us to also examine associations between lake water levels and species abundance. This analysis was based on historical and present survey data for Lake Winnipegosis, which is the site with the most years of complete survey data.

Thus, our goals in this study are to 1) provide an update on abundance and distribution of colonial waterbirds on Lakes Winnipeg, Winnipegosis, and Manitoba and the inter-lake region based on 2017 surveys; 2) examine long-term changes in abundance for the six species in the study region; 3) report on previously unpublished data from the partial surveys of 2011; and 4) analyze patterns of species abundance in relation to water levels on Lake Winnipegosis. Understanding the impact of water level fluctuations on colonial waterbirds in southern Manitoba is especially relevant to their management given the sensitivity of the area to flooding and the fact that water levels are regulated for flood control and hydroelectric activity.

\section{METHODS}

The aerial survey of 2017 included the entire area surveyed by Wilson et al. (2014) in 2012, including all of Lakes Manitoba and Winnipegosis, all of Lake Winnipeg with the exception of the very northern portion, and several of the larger lakes in the inter-lake region (see Wilson et al. 2014 for full details; Fig. 1). In addition, we also surveyed the south end of Lake Winnipeg below $51.0^{\circ} \mathrm{N}$ and the western shore of Shoal Lake, both of which were not included in the 2012 survey. However, for comparisons among complete survey years, only those areas surveyed in all three years are considered (see below). In 2011, Lake Winnipeg between $51.2^{\circ}$ $\mathrm{N}$ and $52.67^{\circ} \mathrm{N}$, most of Lake Winnipegosis save for the northwestern bay, and Dog Lake, Lake Kaweenakumik, and Lake St. Martin in the inter-lake region were surveyed.

Aerial surveys were conducted in mid-June (14 June 2011; 11-12 and 19-20 June 2017) to coincide with the incubation period of the six target species as much as possible. Similar to Wilson et al. (2014), we used digital photography of colonies to obtain adult and nest counts. In 2017, we flew in a Cessna 337 Skymaster fixedwing aircraft, and in 2011 in a Bell 206 helicopter. Flight speeds and altitudes were highly variable. During the fixed-wing survey, we typically travelled quickly and at high altitudes when travelling between breeding colonies, but circled colonies at a slower speed and as low as the pilot was comfortable when taking photographs (175-220 km/hr, 350-450 m). During the helicopter survey, we frequently hovered as needed while taking photographs, at an altitude of $\sim 100-150 \mathrm{~m}$. 
Fig. 1. Location of waterbird colonies on the large lakes of southern Manitoba surveyed during an aerial survey of six target species in June, 2017. Locations where breeding pairs were observed ("colony") as well as locations where only loafing birds were observed ("colony"), are indicated.

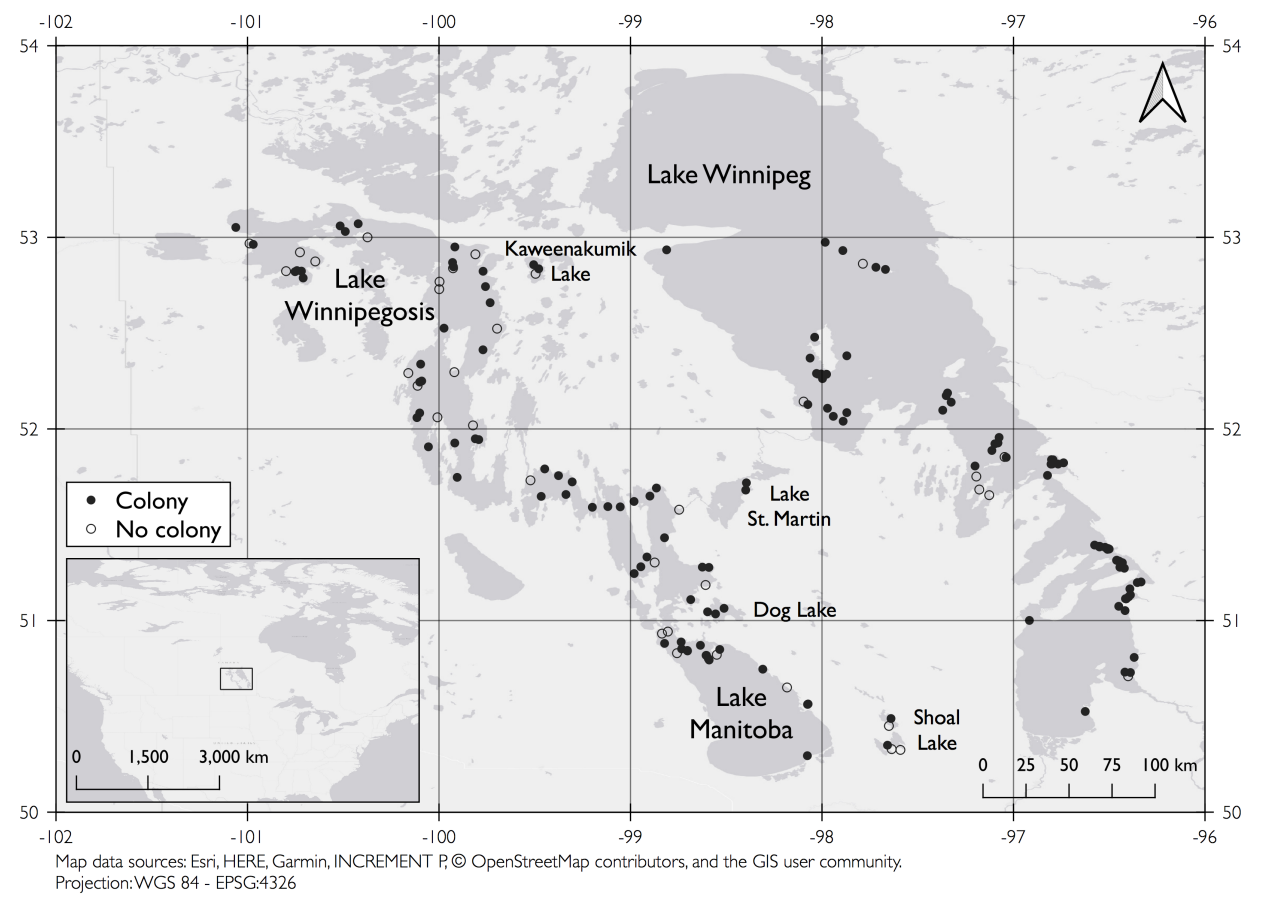

In both years, we initially aimed to visit all historical colony locations as well as any potential new nesting sites on the lakes. However, as described above, given the high water levels and observations of many flooded islands in 2011, the full survey was cancelled partway through and deferred to 2012. During both surveys, a primary photographer seated in the rear right seat of the aircraft took photographs through the window using a D700 Nikon camera in 2011 and a D810 Nikon camera in 2017 and a $400 \mathrm{~mm}$ zoom lens (Nikon Corporation, Minato City, Tokyo, Japan). We approached each potential colony site so that the photographer had a clear view and could take a series of photographs as the aircraft flew past. A secondary photographer, seated in the front right seat, helped coordinate the route and whenever possible took a series of back-up photographs. From the fixed-wing aircraft, if we were not satisfied with the quality or completeness of photographs from the first pass, we would make additional passes. Photographs were taken at any locations where at least one of the target species was observed, regardless of whether a colony was present or the site included only loafing birds. In some instances, if the location looked to contain potential nesting habitat but we did not initially detect any target species (sometimes the case for the more cryptic Common Tern), we would take a series of photographs from the fixed-wing aircraft and check them quickly using the camera zoom function. If a colony was detected in the photographs, the aircraft would make additional passes to obtain a full set of photographs of the colony. Photographs were taken in raw format and set for the highest possible resolution.
Using the above techniques and given that we re-visited all historical colony locations and any new locations that we detected en route, we are confident that we captured all or most colony locations in 2017. If any colonies were missed, they would most likely have been single-species colonies of Common Terns, but these would have likely been on islands with a small number of pairs, thus having a minimal influence on our total count. Nonetheless, given the potential for some missed colonies or undercounting (Frederick et al. 2003; addressed further in the Discussion), our counts should be considered minimum estimates.

Adult birds in photographs were counted using the same protocol as Wilson et al. 2014. In brief, we examined the primary and backup photographs of each colony and selected those that were the highest quality and covered the entire nesting area. We used various landmarks (rocks, woody debris, vegetation) in order to join together photographs of adjacent sections of a colony. We used drawing tools in Adobe Photoshop CS5 in 2011 (Adobe Inc., San Jose, California, USA) or GIMP v. 2.8 in 2017 (The GIMP Development Team 2013) to exclude parts of one image that overlapped with a previously counted image, and to mark all adult birds of the target species. As per Wilson et al. (2014), we estimated the number of nests from counts of incubating birds based on a visible nest structure (Ring-billed Gull, Herring Gull, Doublecrested Cormorant) or the posture of an incubating bird (Caspian Tern, Common Tern, American White Pelican). In a small number of cases, Double-crested Cormorant or American White Pelican eggs had hatched by the time we conducted the survey, and chicks were visible in the nests. If we were not able to confidently assess 
Table 1. Number of breeding pairs (with number of colonies in brackets), median colony size, and maximum colony size for six target species $($ RBGU $=$ Ring-billed Gull, HERG $=$ Herring Gull, CATE $=$ Caspian Tern, COTE $=$ Common Tern, DCCO = Double-crested Cormorant, AWPE = American White Pelican) nesting on Lakes Winnipeg, Winnipegosis, and Manitoba and the inter-lake region during aerial surveys in June, 2017.

\begin{tabular}{|c|c|c|c|c|c|c|c|c|}
\hline Species & Winnipeg & Winnipegosis & Manitoba & Inter-lake & Total & $\begin{array}{l}\% \text { Canadian } \\
\text { population }^{\dagger}\end{array}$ & $\begin{array}{c}\text { Median colony } \\
\text { size }\end{array}$ & Max colony size \\
\hline RBGU & $14,623(37)$ & 2,177 (13) & $14,226(12)$ & $6,961(5)$ & 37,987 (67) & $3.8-7.6$ & 201 & 5,017 \\
\hline HERG & $3,269(59)$ & $158(16)$ & $338(26)$ & $47(5)$ & $3,812(106)$ & $2.5-3.8$ & 14 & 422 \\
\hline CATE & $939(10)$ & $281(8)$ & $450(3)$ & $31(2)$ & $1,701(23)$ & $6.8-13.6$ & 29 & 441 \\
\hline COTE & $3,830(15)$ & $1,087(7)$ & $289(3)$ & $107(1)$ & $5,313(26)$ & $5.3-10.6$ & 98 & 1,109 \\
\hline $\mathrm{DCCO}$ & $6,322(18)$ & $11,685(16)$ & $11,133(23)$ & $4,766(6)$ & $33,906(63)$ & $13.6-17.0$ & 159 & 5,357 \\
\hline AWPE & $6,644(23)$ & $1,058(16)$ & $3,206(13)$ & $7,613(3)$ & $18,521(55)$ & $18.5-37.0$ & 32 & 3,509 \\
\hline
\end{tabular}

${ }^{\dagger}$ based on population estimate range provided by The Status of Birds in Canada (ECCC 2019).

incubation posture for a portion or for the entirety of a colony (sometimes the case with Common Terns due to their small size and plain scrape nests, due to poor-quality images, or because part of the colony would sometimes flush as we approached), we used the species-specific adult-to-nest ratio from the rest of the colony or from all colonies combined, respectively, to estimate the number of nests. We considered the number of nests at each colony to represent the estimated number of breeding pairs.

In order to compare counts of breeding pairs over time, we compiled available published data from colonial waterbird surveys conducted in southern Manitoba since 1969 (Appendix 1, Table A1.1). We considered data from surveys that covered the entire region (Lake Winnipeg, Lake Winnipegosis, Lake Manitoba, and the inter-lake region), as well as surveys that covered portions of the region (hereafter 'partial surveys'). We considered surveys that included all species or a subset of the target species. Full details including survey methodology, dates, and sources can be found in Appendix 1 (Table A1.1).

Because the general locations of surveyed areas were available from certain surveys (Koonz and Rakowski 1985, Vermeer 1969, 1970), and the precise geographic coordinates and names of colonies from Wilson et al. (2014) were available, we were able to exclude any areas that were not surveyed in all years for the full comparison. This also enabled us to include subsets of the full datasets (e.g., Lake Winnipegosis only) when comparing the above with the partial surveys. Unfortunately, given a lack of detailed descriptive locational information or geographic coordinates of island from all survey years, we were not able to make comparisons on a colony-by-colony basis.

One additional caveat is that we did not have locational information from the full regional surveys of Caspian Terns in 1986 and 1990 (Wires and Cuthbert 2000). Instead, these are cited as "Regional Total - Southern Manitoba" and thus may have included some areas that were not surveyed in 1979, 2012, and 2017. However, the colonies we excluded from the 1979 survey accounted for only $1.4 \%$ of the total number of pairs of Caspian Terns, and therefore it is likely that the full regional counts of 1986 and 1990 are reasonably comparable to the counts from the other three full survey years.

To examine possible relationships between numbers of breeding pairs and water levels, we focused on survey data from Lake Winnipegosis, which had the most complete time series (4-6 data points per species, for a total of 28 data points). The next most complete time series was for all lakes combined, but with only 22 data points we did not feel this to be sufficient for analysis. We obtained historical hydrometric data for Lake Winnipegosis from Environment and Climate Change Canada's Water Office (ECCC 2020), and used the average water level in June from the Lake Winnipegosis at Winnipegosis station (05LH001), for which data were available in all years of interest. We constructed a generalized linear model using the negative binomial family. The model used number of breeding pairs as the response variable and water level (m) and species as fixed effects. We examined an alternate model with year in place of water level. We could not include both year and water level in the same model due to correlation between them $(r=0.77)$. We evaluated the significance of fixed effects using a chi-square test to examine the difference in deviance between the full model and a sub-model with the given fixed effect removed. Analyses were performed in R v. 3.6.3 (R Core Team 2013).

\section{RESULTS}

We detected at least one target species present at 178 locations on the lakes in 2017 , with a breeding colony of at least one species occurring at 144 locations $(81 \%)$, and 34 locations with loafing birds only (Fig. 1). The most abundant species observed during our surveys was the Ring-billed Gull, with 37,987 breeding pairs at 67 colonies (Table 1). Caspian Terns were the least abundant, with 1,701 breeding pairs at 23 colonies. All four tern and gull species were most abundant on Lake Winnipeg, whereas Doublecrested Cormorant was most abundant on Lake Winnipegosis, with similarly high numbers found on Lake Manitoba. Interestingly, American White Pelicans were most abundant in the inter-lake region, with a total of 7,613 breeding pairs occurring at just three colonies. Ring-billed Gulls and Doublecrested Cormorants had the largest maximum and median colony sizes, whereas Herring Gulls and Caspian Terns had the smallest (Table 1).

Ring-billed Gull, Herring Gull, and Double-crested Cormorant populations on all lakes combined increased from the initial surveys of the 1960s and 1970s to the 2012 survey, but declined in 2017 (Fig. 2). A similar but stronger pattern was found for the tern species, which appeared to increase from the initial surveys of the 1960s and 1970s to a peak in the 1990s, followed by declines in recent years back to levels similar to the early survey years. American White Pelicans were the only species found to show a 
Fig. 2. Trends over time in numbers of breeding pairs of six species of colonial waterbirds on the large lakes of southern Manitoba (RBGU = Ring-billed Gull, HERG = Herring Gull, CATE $=$ Caspian Tern, COTE $=$ Common Tern, DCCO = Double-crested Cormorant, AWPE $=$ American White Pelican). For Caspian Terns on Lake Winnipegosis and Common Terns on all lakes but Lake Winnipegosis in 1990, ranges of values were provided by the data source and are shown here. All data sources can be found in Appendix 1.

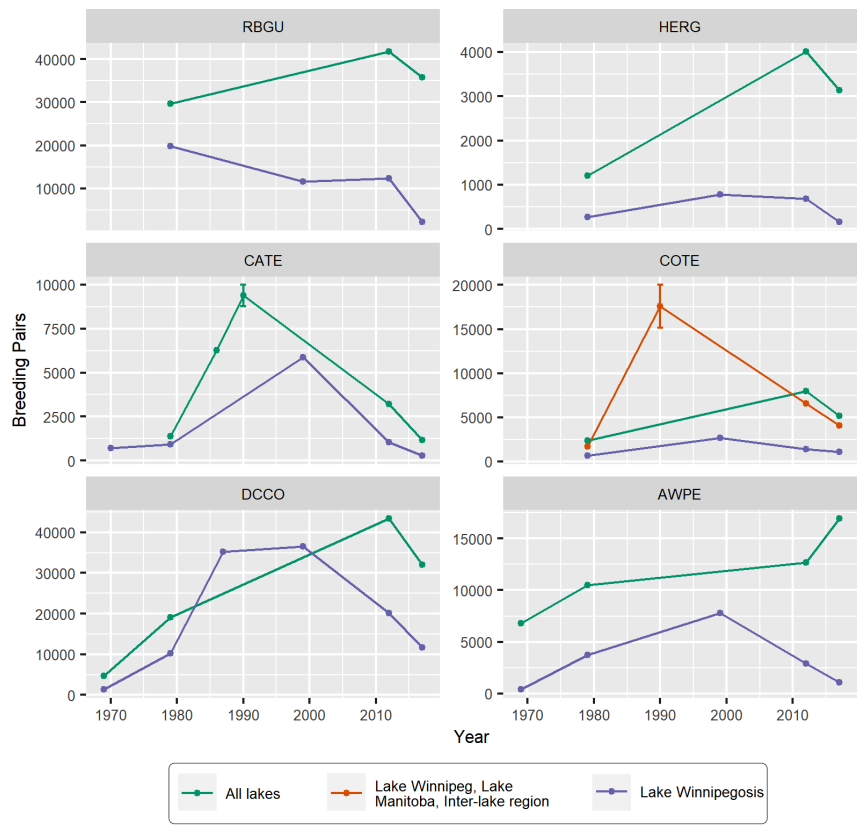

continued increase over time on all lakes (Fig. 2). Patterns on Lake Winnipegosis, which had the most comprehensive time series of surveys, were more variable, but trends for all species including American White Pelicans showed declines in recent years. When examining location-specific differences between the two most recent surveys (2012 and 2017), changes in overall breeding pair abundance can be attributed to both changes in colony occupancy and abundance for each species (Appendix 2, Figs A2.1-2.6). For example, there were more Caspian Tern breeding pairs in total but at fewer colonies in 2012, with a correspondingly larger average colony size (Fig. A2.2).

The 2011 survey involved visits to 23 historically occupied colony sites on lakes Winnipeg, Winnipegosis, Kaweenakumik, and St. Martin, and Dog lakes. Of these, 11 sites (48\%) were completely flooded and/or had no breeding target species. In contrast, at the same 23 sites in 2012 and 2017, each one was occupied by a colony of at least one breeding target species in 2012, and $19(83 \%)$ were occupied by a colony of at least one breeding target species in 2017. Overall, there was anywhere from 3x (Common Tern) to 44x (Ring-billed Gull) fewer breeding pairs in 2011 compared to 2012 at these 23 sites (Appendix 3, Table A3.1).

Both water level on Lake Winnipegosis $\left(X^{2}{ }_{1}=7.7, P=0.005\right)$ and species $\left(X_{5}^{2}=75.2, P<0.001\right)$ were significant predictors of the number of breeding pairs on Lake Winnipegosis. Higher water
Fig. 3. Association between annual number of breeding pairs and lake water levels for six species of colonial waterbirds breeding on Lake Winnipegosis (RBGU = Ring-billed Gull, HERG $=$ Herring Gull, CATE $=$ Caspian Tern, COTE $=$ Common Tern, DCCO $=$ Double-crested Cormorant, AWPE $=$ American White Pelican). A model of the number of breeding pairs as a function of water level and species was fitted with a negative binomial error distribution.

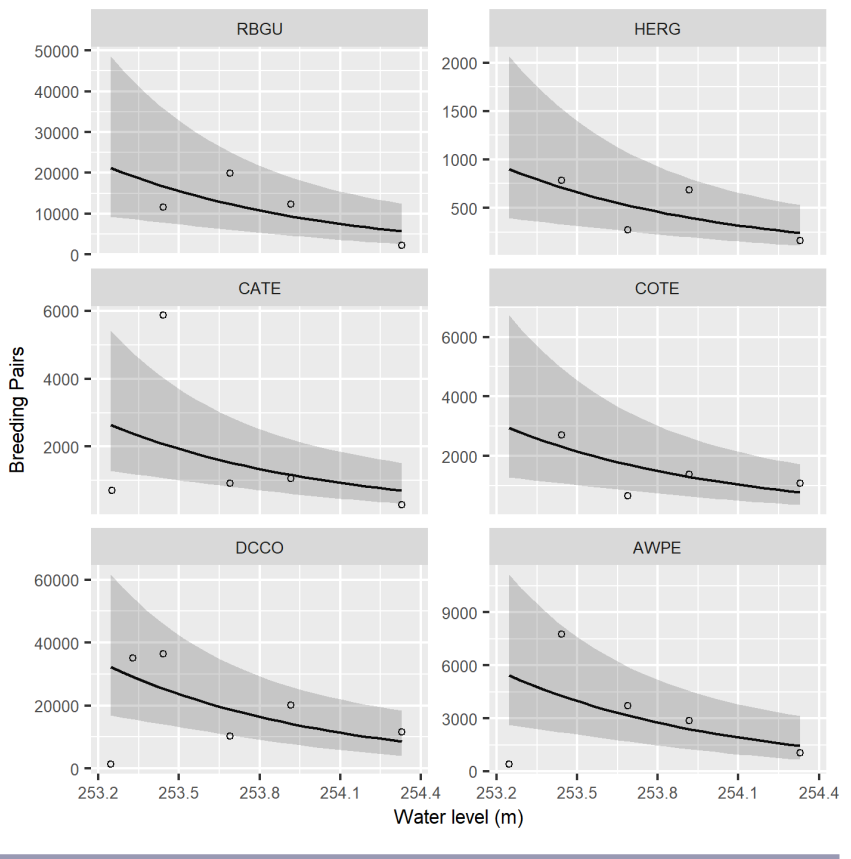

levels were associated with fewer breeding pairs (Fig. 3). In a separate model, year was not a significant predictor of the number of breeding pairs $\left(X^{2}=0.1, P=0.75\right)$, but species remained so $\left(X^{2}{ }_{5}=62.1, P<0.001\right)$.

\section{DISCUSSION}

The large lakes of southern Manitoba - Lakes Winnipeg, Winnipegosis, and Manitoba - and the associated inter-lake region host nationally significant populations of colonial waterbirds. In 2017, up to $37 \%$ and $17 \%$ of the total estimated Canadian populations of American White Pelicans and Doublecrested Cormorants, respectively, bred in this region. Important numbers of Ring-billed Gulls (4-8\% of Canadian population), Herring Gulls (3-4\%), Caspian Terns (7-14\%) and Common Terns $(5-11 \%)$ were found nesting here as well (Table 1). For all species but the American White Pelican, initial increases in abundance on all lakes since the first surveys in the 1960s or 1970s were followed by lower abundances in recent years. The same pattern was generally true for Lake Winnipegosis, which had the most comprehensive time series of surveys, with the exception that abundance of American White Pelicans was also lower here in recent years. Notably, Caspian Tern and Common Tern populations in 2017 were as low as or just above 1970s levels, respectively. An analysis of breeding pair abundance on Lake Winnipegosis in relation to water levels revealed that higher water 
levels were associated with fewer breeding pairs on the lake, while year was not significantly related to abundance, likely due to the fluctuations indicated above in contrast to a linear trend over time.

One important assumption when comparing results across surveys is that different survey methodologies produce relatively comparable counts of colonially nesting waterbirds (see Wilson et al. 2014 for detailed discussion). Surveys of the southern Manitoba lakes have made use of mixed aerial visual counts and ground counts, aerial counts based on digital photography, ground counts, and boat-based counts (Appendix 1, Table A1.1). While ground counts are generally considered the most accurate method, they are time consuming and highly disruptive (McKellar et al. 2019), and would not have been practical in our case. Aerial counts tend to underestimate the true number of breeding pairs (Frederick et al. 2003, Rodgers et al. 2005; but see Green et al. 2008), but the use of photography has been shown to improve estimates (Dolbeer et al. 1997, Frederick et al. 2003). In our time series, the 2012 and 2017 survey results should be considered most comparable given their identical methodology. Nonetheless, we feel that the broad patterns observed likely hold true even if counts from some years are more accurate (i.e., those when ground counts were used), especially given the large fluctuations in numbers of breeding pairs we observed and because ground counts tended to be used in surveys of smaller spatial scope. A second caveat is that with a relatively limited time series, it is difficult to draw inferences regarding trends over time, especially given the effects of water levels we identified. This challenge highlights the value of continued monitoring to generate longer time series for trend analysis, perhaps with monitoring taking place in years when water levels fall within a pre-determined range (see below for further survey and research recommendations). We acknowledge, however, that the latter approach would be logistically difficult given the advanced planning required for a large-scale survey.

We had expected a negative association between water levels on Lake Winnipegosis and numbers of breeding pairs of colonial waterbirds. High water levels can cause nesting islands to either be completely submerged, or at the very least reduce the available land area for nesting. Indeed, breeding pair abundance was much lower in the flood year of 2011, and many islands were submerged, when comparing the subset of sites surveyed in 2011, 2012, and 2017. This appeared to affect Ring-Billed Gulls (e.g., 44x fewer breeding pairs in 2011 compared to 2012) and American White Pelicans (26x fewer breeding pairs) to a greater degree than the other four species, perhaps due to their tendency to form larger breeding colonies, although the same was not true for Doublecrested Cormorants ( $3.5 \mathrm{x}$ fewer breeding pairs), which also form large colonies (Appendix 3, Table A3.1). The effects of high water levels were also apparent when comparing photographs of specific sites between 2012, when water levels were generally lower, and 2017 (Fig. 4). However, periodic flooding may have positive effects through restricting woody vegetation growth (Evans 1972). Higher water levels may even create additional nesting habitat. For example, during surveys in 2017 we discovered a nesting colony of American White Pelicans on a newly created island where there was formerly a continuous strip of land between East and West Shoal Lakes in the inter-lake region (see also Poole 2018).
Fig. 4. Portion of a reef on Lake St. Martin, Manitoba, occupied by nesting Double-crested Cormorants in (a) 2012 and (b) 2017.

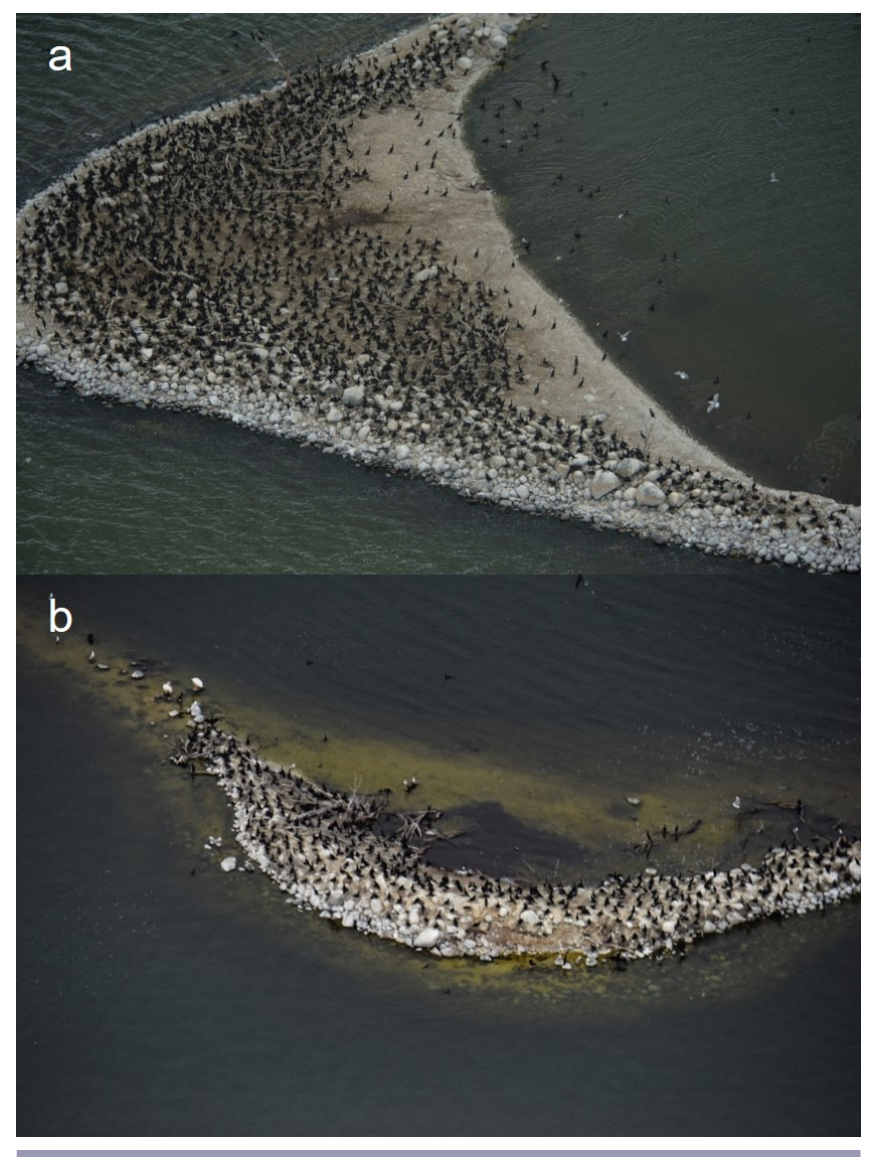

Water levels on Lakes Manitoba and Winnipeg are regulated for flood management and hydroelectric activity. There has been an overall reduction in water level variation on the lakes since regulation began but also more extreme water level fluctuations on some lakes in the inter-lake region as a result (Lake Manitoba Regulatory Review Advisory Committee 2003, Hesslein 2011). Nonetheless, despite regulation, we would still expect a generally negative relationship between annual water level on the lakes and colonial waterbird abundance, as was seen on Lake Winnipegosis. On Lake Winnipeg, Manitoba Hydro is licensed to regulate the water levels between 216.7 and $217.9 \mathrm{~m}$ (711-715 feet) above sea level, which was determined to be within the historical range of 216.1-218.7 m (709-717.5 feet) (Clean Environment Commission 2015). Lake Manitoba is managed to a target level of $247.5 \mathrm{~m}$ (812.2 feet) (Lake Manitoba Regulatory Review Advisory Committee 2003). Since control structures were completed on Lake Winnipeg in 1976, Manitoba Hydro calculated that average levels were $6 \mathrm{~cm}(0.2 \mathrm{feet})$ higher than historical levels. It is important to note, however, that the inflow capacity to the lake is greater than the outflow created through regulation, so it is still possible for the levels to rise above the maximum specified level, and for lake levels to show substantial variation across the lake. Optimal regulation of water levels on Lake Winnipeg is a 
challenge because it must balance multiple needs. Communities and residents have highlighted issues such as high water levels, excessive local flooding, and erosion, while Manitoba Hydro has countered that flooding would have been much worse without regulation in place (Clean Environment Commission 2015). While it is clear that regulation has helped control flooding caused by high precipitation in recent years, the stabilization of water levels (thus preventing the scouring of vegetation on islands; Goossen and Porteous 2017), alongside climate change predictions that include increased runoff, likely pose a greater threat to colonial waterbirds in the long-term than slight increases in average water levels per se.

An important question is whether surveys of colonial waterbirds at regular intervals on the large lakes of southern Manitoba are an accurate indicator of population trends for these species over a larger region, such as the Canadian prairie provinces as a whole. Decadal colonial waterbird surveys in the Great Lakes Region of the U.S. and Canada have been used to infer inland colonial waterbird trends, but interpretation of those trends is mostly restricted to that region (Weseloh et al. 2002, Morris et al. 2010, 2011). Recent work has shown that the boreal forest of Ontario may contain significant populations of some species such as Common Terns (D. Moore, pers. comm.). Similarly, Wilson(2013) found that densities of Common Terns and Herring Gulls on boreal lakes in a small area of west-central Manitoba and eastcentral Saskatchewan were higher than those found on lakes Manitoba and Winnipegosis. If breeding populations on the large lakes of southern Manitoba are linked to water levels, and the boreal forest contains sufficient suitable habitat, it is possible that individuals may overfly southern Manitoba in high-water years and settle further north, as appears to occur in some waterfowl species (Johnson and Grier 1988). If this is the case, population trends in southern Manitoba may not be reflective of the larger region. The same may be true if the boreal forest hosts a substantial portion of the regional population of these species, and if they are subject to different drivers of population change there than in southern Manitoba. More research is needed to quantify waterbird population sizes and habitat associations in the western boreal forest, and population synchrony between boreal and southern regions and how this relates to water levels. In any case, the lower breeding abundance of Ring-billed Gull, Herring Gull, and Common Tern populations in southern Manitoba in recent years mirrors trends for these species in the Great Lakes Region (Morris et al. 2010, 2011, ECCC 2019), which may reflect larger-scale processes affecting North American populations of inland colonial waterbirds.

\section{CONCLUSION}

We recommend continued monitoring of colonial waterbirds in southern Manitoba, possibly using a survey protocol that takes lake levels into consideration. Ideally, this would also be done in conjunction with the Great Lakes monitoring schedule, which is currently being revised to involve more frequent surveys at a subset of the most important colonies, with reconnaissance surveys every 10-15 years to determine which sites require the more frequent surveys (Cuthbert and Wires 2013). However, given the much smaller overall area compared to the Great Lakes, and the remoteness of the large lakes of southern Manitoba, it is feasible and likely more practical to conduct a full survey of all colony sites in this area at regular intervals rather than at a subset of sites. Additional research is needed to understand the effects of water levels and periodic flooding on habitat suitability for colonial waterbirds in southern Manitoba. Factors other than water levels, such as island characteristics and presence of conesters, may also influence colony occupancy (Wyman et al. 2014), and these effects warrant study in Manitoba. Work is needed to quantify population sizes and habitat associations in the western boreal forest. Finally, future surveys should test the use of technologies that could save time, money, and potentially reduce observer error and increase the accuracy of counts, such as a geo-referenced high-resolution camera system mounted directly to an aircraft, automated stitching of sequential photographs, and computer-automated procedures for counting nests in imagery (Chabot and Francis 2016, Bakó et al. 2020).

\section{Responses to this article can be read online at: https://www.ace-eco.org/issues/responses.php/1789}

\section{Acknowledgments:}

R. Bazin assisted with field work, J. Dunne-Mucklow and $N$. Shephard provided GIS support, and N. Shephard helped with data analysis. C. Artuso and T. Poole provided helpful background information on water level regulation in Manitoba. Air charter services were contracted through Prairie Helicopters Inc. and Discovery Air Fire Services. Funding was provided by Environment and Climate Change Canada.

\section{LITERATURE CITED}

Amano, T., T. Skékely, B. Sandel, S. Nagy, T. Mundkur, T. Langendoen, D. Blanco, C. U. Soykan, and W. J. Sutherland. 2017. Successful conservation of global waterbird populations depends on effective governance. Nature 553:199-202. https://doi. org/10.1038/nature25139

Bakó, G., Z. Molnár, Z. Szilágyi, C. Biró, E. Morvai, O. Ábrám, and A. Molnár. 2020. Accurate non-disturbance population survey method of nesting colonies in the reedbed with georeferenced aerial imagery. Sensors 20:2601. https://doi. org/10.3390/s20092601

Brimelow, J., R. Stewart, J. Hanesiak, B. Kochtubajda, K. Szeto, and B. Bonsal. 2014. Characterization and assessment of the devastating natural hazards across the Canadian Prairie provinces from 2009 to 2011. Natural Hazards 73:761-785. https://doi. org/10.1007/s11069-014-1107-6

Chabot, D., and C. M. Francis. 2016. Computer-automated bird detection and counts in high-resolution aerial images: a review. Journal of Field Ornithology 87:343-359. https://doi.org/10.1111/ jofo. 12171

Clean Environment Commission. 2015. Lake Winnipeg Regulation Report 2015. Manitoba Clean Environment Commission, Winnipeg, Manitoba, Canada. [online] URL: http://www.cecmanitoba.ca/cecm/hearings/pubs/

Lake_Winnipeg_Regulation_-_Manitoba_Hydro/FinalReport/ LWR_WEB.pdf. 
Cotter, R. C., J.-F. Rail, A. W. Boyne, G. J. Robertson, D. V. C. Weseloh, and K. G. Chaulk. 2012. Population status, distribution, and trends of gulls and kittiwakes breeding in eastern Canada, 1998-2007. Canadian Wildlife Service Occasional Paper No. 120. Environment Canada, Ottawa, Ontario, Canada. 96 pp.

Cuthbert, F. J., and L. R. Wires. 2013. Long-term monitoring of colonial waterbird populations in the U.S. great lakes: Improving the scientific basis for conservation and management. Final Report (February 2013) to U.S. Fish and Wildlife Service, Fort Snelling, Minnesota, USA.

Dolbeer, R. A., J. L. Belant, and G. E. Bernhardt. 1997. Aerial photography techniques to estimate populations of Laughing Gulls in Jamaica Bay, New York, 1992-1995. Colonial Waterbirds 20:8-13. https://doi.org/10.2307/1521758

ECCC (Environment and Climate Change Canada). 2019. The Status of Birds in Canada Website, Data-version 2019. Environment and Climate Change Canada, Gatineau, Quebec, Canada. [online] URL: https://wildlife-species.canada.ca/birdstatus/.

ECCC (Environment and Climate Change). 2020. Environment and Climate Change Canada Historical Hydrometric Data. [online] URL: https://wateroffice.ec.gc.ca/mainmenu/ historical_data_index_e.html.

Erwin, R. M., J. D. Nichols, T. B. Eyler, D. B. Stotts, and B. R. Truitt. 1998. Modeling colony-site dynamics: a case study of GullBilled Terns (Sterna nilotica) in coastal Virginia. Auk 115:970-978. https://doi.org/10.2307/4089515

Evans, R. M. 1972. Some effects of water level on reproductive success of the White Pelican at East Shoal Lake, Manitoba. Canadian Field-Naturalist 86:151-153.

Frederick, P. A., B. H. Hylton, J. A. Heath, and M. Ruane. 2003. Accuracy and variation in estimates of large numbers of birds by individual observers using an aerial survey simulator. Journal of Field Ornithology 74:281-287. https://doi.org/10.1648/0273-8570-74.3.281

Goossen, J. P., and K. Porteous. 2017. Manitoba's declining Piping Plover population and the importance of special conservation areas. Blue Jay 75:9-16. https://doi.org/10.29173/ bluejay 7

Green, M. C., M. C. Luent, T. C. Michot, C. W. Jeske, and P. L. Leberg. 2008. Comparison and assessment of aerial and ground estimates of waterbird colonies. Journal of Wildlife Management 72:697-706. https://doi.org/10.2193/2006-391

Hesslein, R. H. 2011. An Assessment of the effect of regulation of the outflow of Lake Winnipeg on the levels of the lake. Prepared for the Lake Winnipeg Foundation. 7p.

Johnson, D. H., and J. W. Grier. 1988. Determinants of breeding distributions of ducks. Wildlife Monographs 100:1-37.

Koonz, W. H., and P. W. Rakowski. 1985. Status of colonial nesting waterbirds in southern Manitoba. Canadian FieldNaturalist 99:19-29.

Kushlan, J. A., M. J. Steinkamp, K. C. Parsons, J. Capp, M. A. Cruz, M. Coulter, I. Davidson, L. Dickson, N. Edelson, R. Elliot, R. M. Erwin, S. Hatch, S. Kress, R. Milko, S. Miller, K. Mills, R.
Paul, R. Phillips, J. E. Saliva, B. Sydeman, J. Trapp, J. Wheeler, and K. Wohl. 2002. Waterbird conservation for the Americas: The North American waterbird conservation plan, version 1. Waterbird Conservation for the Americas, Washington, DC, USA.

Lake Manitoba Regulation Review Advisory Committee. 2003. Regulation of Water Levels on Lake Manitoba and Along the Fairford River, Pineimuta Lake, Lake St. Martin and Dauphin River and Related Issues: A Report to the Manitoba Minister of Conservation, Volume 2: Main Report. Manitoba Conservation.

McKellar, A. E., L. A. Nych, and M. T. Bidwell. 2019. Distribution and abundance of marsh-nesting colonial waterbirds in Prairie Canada. Wilson Journal of Ornithology 131:583-597. https://doi.org/10.1676/18-180

Moreno-Matiella L. A., and D. W. Anderson. 2005. Nesting habitat configuration and availability for the American White Pelican at Clear Lake Reservoir, California. Waterbirds 28:73-82. https://doi.org/10.1675/1524-4695(2005)28[73:WLVAIE]2.0.CO;2

Morris, R. D., D. V. Weseloh, F. J. Cuthbert, C. Pekarik, L. R. Wires, and L. Harper. 2010. Distribution and abundance of nesting Common and Caspian Terns on the North American Great Lakes, 1976 to 1999. Journal of Great Lakes Research 36:44-56. https://doi.org/10.1016/j.jglr.2009.09.008

Morris, R. D., D. V. Weseloh, L. R. Wires, C. Pekarik, F. J. Cuthbert, and D. J. Moore. 2011. Population trends of Ring-billed Gulls breeding on the North American Great Lakes, 1976 to 2009. Waterbirds 34:202-212. https://doi.org/10.1675/063.034.0209

NABCI Canada (North American Bird Conservation Initiative Canada). 2019. The State of Canada's Birds, 2019. Environment and Climate Change Canada, Ottawa, Canada. 12 pp.

Poole, T. F. 2018. American White Pelican. In C. Artuso, A. R. Couturier, K. D. De Smet, R. F. Koes, D. Lepage, J. McCracken, R. D. Mooi, and P. Taylor, editors. The Atlas of the Breeding Birds of Manitoba, 2010-2014. Bird Studies Canada, Winnipeg, Manitoba, Canada. [online] URL: http://www.birdatlas.mb.ca/ accounts/speciesaccount.jsp?sp=AWPE\&lang=en

Rodgers, J. A., Jr., P. S. Kubilis, and S. A. Nesbitt. 2005. Accuracy of aerial surveys of waterbird colonies. Waterbirds 28:230-237. https://doi.org/10.1675/1524-4695(2005)028[0230:AOASOW]2.0. $\mathrm{CO} ; 2$

Vermeer, K. 1969. The present status of Double-crested Cormorant colonies in Manitoba. Blue Jay 27:217-220. https:// doi.org/10.29173/bluejay3420

Vermeer, K. 1970. Distribution and size of colonies of white pelicans, Pelecanus erythrorhynchos, in Canada. Canadian Journal of Zoology 48:1029-1032. https://doi.org/10.1139/z70-180

Weseloh, D. V., C. Pekarik, T. Havelka, G. Barrett, and J. Reid. 2002. Population trends and colony locations of Double-crested Cormorants in the Canadian Great Lakes and immediately adjacent areas, 1990-2000: a manager's guide. Journal of Great Lakes Research 28:125-144. https://doi.org/10.1016/S0380-1330 (02)70571-6

Wilson, S. 2013. Abundance, distribution, and species assemblages of colonial waterbirds in the boreal region of west- 
central Manitoba and east-central Saskatchewan. Canadian Field-Naturalist 127:203-210. http://dx.doi.org/10.22621/cfn. v127i3.1483

Wilson, S., R. Basin, W. Calvert, T. J. Doyle, S. D. Earsom, S. A. Oswald, and J. M. Arnold. 2014. Abundance and trends of colonial waterbirds on the large lakes of southern Manitoba. Waterbirds 37:233-244. https://doi.org/10.1675/063.037.0302

Wires, L. R., and F. J. Cuthbert. 2000. Trends in Caspian Tern numbers and distribution in North America: a review. Waterbirds 23:388-404. https://doi.org/10.2307/1522176

Wyman K. E., L. R. Wires, and F. J. Cuthbert. 2014. Colonial waterbird site occupancy dynamics reflect variation in colony site environments in the U.S. Great Lakes. Journal of Great Lakes Research 40:956-963. http://dx.doi.org/10.1016/j.jglr.2014.09.013

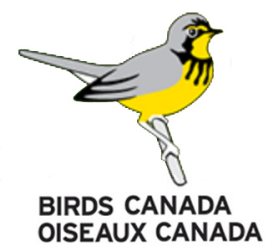


Appendix 1. Details regarding historical and current colonial waterbird surveys on the large lakes of southern Manitoba, Canada.

Table A1.1. Colonial waterbird surveys conducted between 1969 and 2017 in southern Manitoba. Details include survey dates when available, the portion of the region surveyed (where 'Whole region' = Lake Winnipeg, Lake Winnipegosis, Lake Manitoba, and the Interlake region), survey method when available (where 'Aerial' = fixed wing, helicopter, or a combination; 'Boat' = counts made from a boat; 'Ground' = counts made within the colony; or a combination), and species included in the survey.

\begin{tabular}{|c|c|c|c|c|c|}
\hline Year & Dates & Area surveyed & Survey method & Species & Reference \\
\hline 1969 & $\begin{array}{l}\text { "when the eggs } \\
\text { started to hatch" }\end{array}$ & Whole region & $\begin{array}{l}\text { Aerial (visual)/ } \\
\text { Ground }\end{array}$ & $\begin{array}{l}\text { DCCO, } \\
\text { AWPE }\end{array}$ & Vermeer $1969,1970 a$ \\
\hline 1970 & 24 June & Lake Winnipegosis $†$ & Ground & CATE & Vermeer $1970 b$ \\
\hline 1979 & $11,12,19$ June & Whole region & $\begin{array}{l}\text { Aerial (visual)/ } \\
\text { Ground }\end{array}$ & All species & $\begin{array}{l}\text { Koonz and Rakowski } \\
1985\end{array}$ \\
\hline 1986 & NA & Whole region & NA & CATE & $\begin{array}{l}\text { B. Koonz, cited in Wires } \\
\text { and Cuthbert } 2000\end{array}$ \\
\hline 1987 & Late June & Lake Winnipegosis & Boat/Ground & $\mathrm{DCCO}$ & Hobson et al. 1989 \\
\hline $1989-92$ & NA & Whole region & NA & CATE & $\begin{array}{l}\text { B. Koonz, cited in Wires } \\
\text { and Cuthbert } 2000\end{array}$ \\
\hline 1990 & NA & $\begin{array}{c}\text { Lake Winnipeg, Lake } \\
\text { Manitoba, Inter-lake } \\
\text { region }\end{array}$ & NA & COTE & $\begin{array}{c}\text { Manitoba Conservation, } \\
\text { as cited in Wilson et al. } \\
2014\end{array}$ \\
\hline 1999 & 4-11 June & Lake Winnipegosis & Boat/Ground & All species & Koonz 2000 \\
\hline 2012 & 13, 15, 16 June & Whole region & Aerial (photography) & All species & Wilson et al. 2014 \\
\hline 2017 & $11,12,19,20$ June & Whole region & Aerial (photography) & All species & Current study \\
\hline
\end{tabular}

\section{LITERATURE CITED}

Hobson, K. A., R. W. Knapton, and W. Lysack. 1989. Population, diet and reproductive success of Double-crested Cormorants breeding on Lake Winnipegosis, Manitoba, in 1987. Colonial Waterbirds 12:191-197.

Koonz, W. H. 2000. Some bird observations in Manitoba in 1999. Blue Jay 58:65-66. https://doi.org/10.29173/bluejay5653 
Koonz, W. H., and P. W. Rakowski. 1985. Status of colonial nesting waterbirds in southern Manitoba. Canadian FieldNaturalist 99:19-29.

Vermeer, K. 1969. The present status of Double-crested Cormorant colonies in Manitoba. Blue Jay 27:217-220. https://doi.org/10.29173/bluejay3420

Vermeer, K. 1970a. Distribution and size of colonies of white pelicans, Pelecanus erythrorhynchos, in Canada. Canadian Journal of Zoology 48:1029-1032. https://doi.org/10.1139/z70-180

Vermeer, K. 1970b. Large colonies of Caspian Terns on Lakes Winnipeg and Winnipegosis, 1970. Blue Jay 28:117-118. https://doi.org/10.29173/bluejay3733

Wilson, S., R. Basin, W. Calvert, T. J. Doyle, S. D. Earsom, S. A. Oswald, and J. M. Arnold. 2014. Abundance and trends of colonial waterbirds on the large lakes of southern Manitoba. Waterbirds 37:233-244. https://doi.org/10.1675/063.037.0302

Wires, L. R., and F. J. Cuthbert. 2000. Trends in Caspian Tern numbers and distribution in North America: a review. Waterbirds 23:388-404. https://doi.org/10.2307/1522176 
Appendix 2. Differences between 2012 and 2017 colony presence and size for colonial waterbird species (Ring-billed Gull, Herring Gull, Caspian Tern, Common Tern, Double-crested Cormorant, American White Pelican) on the large lakes of southern Manitoba, Canada.

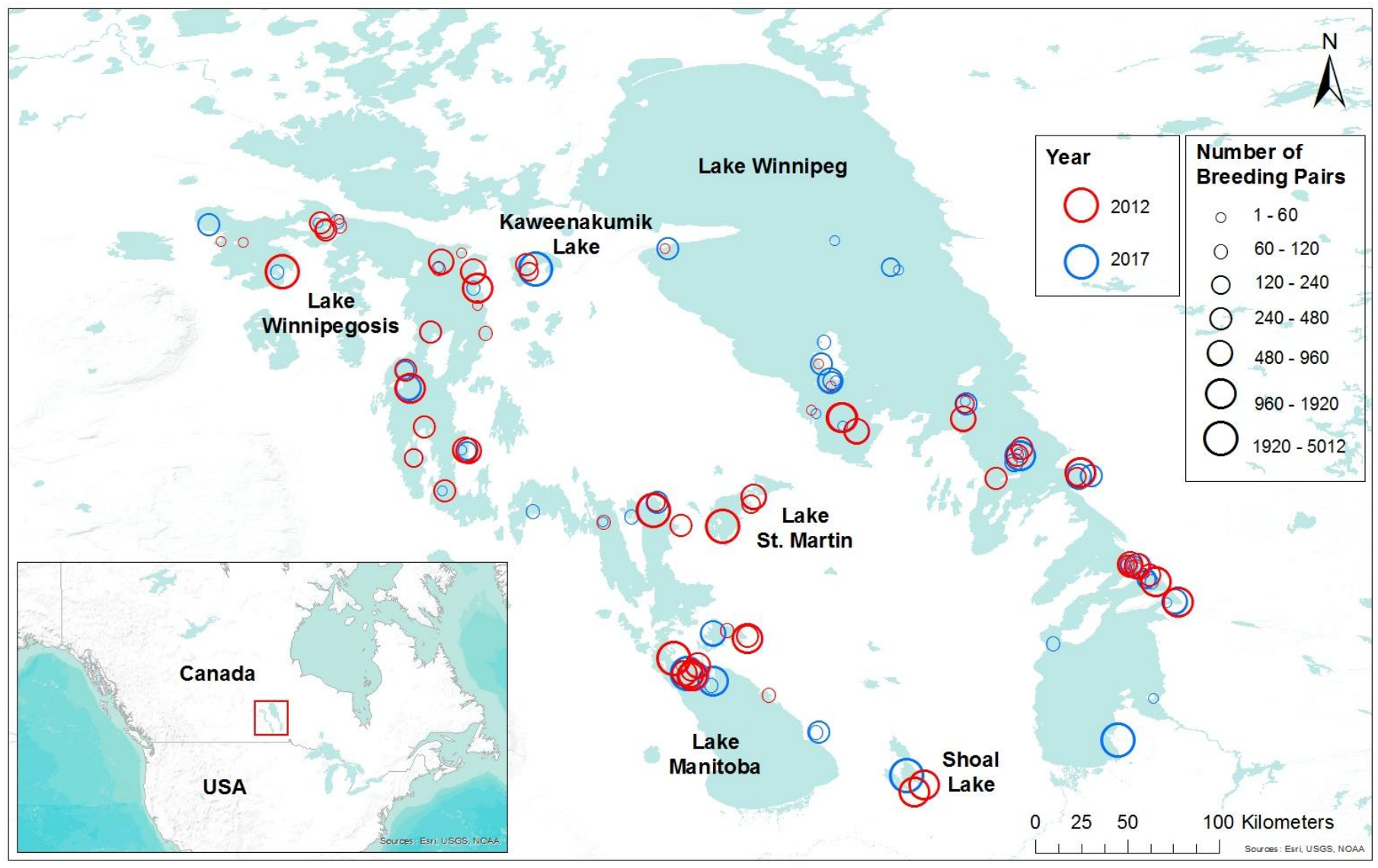

Figure A2.1. Number of breeding pairs of Ring-billed Gulls on the large lakes of southern Manitoba based on aerial surveys conducted in 2012 and 2017. 


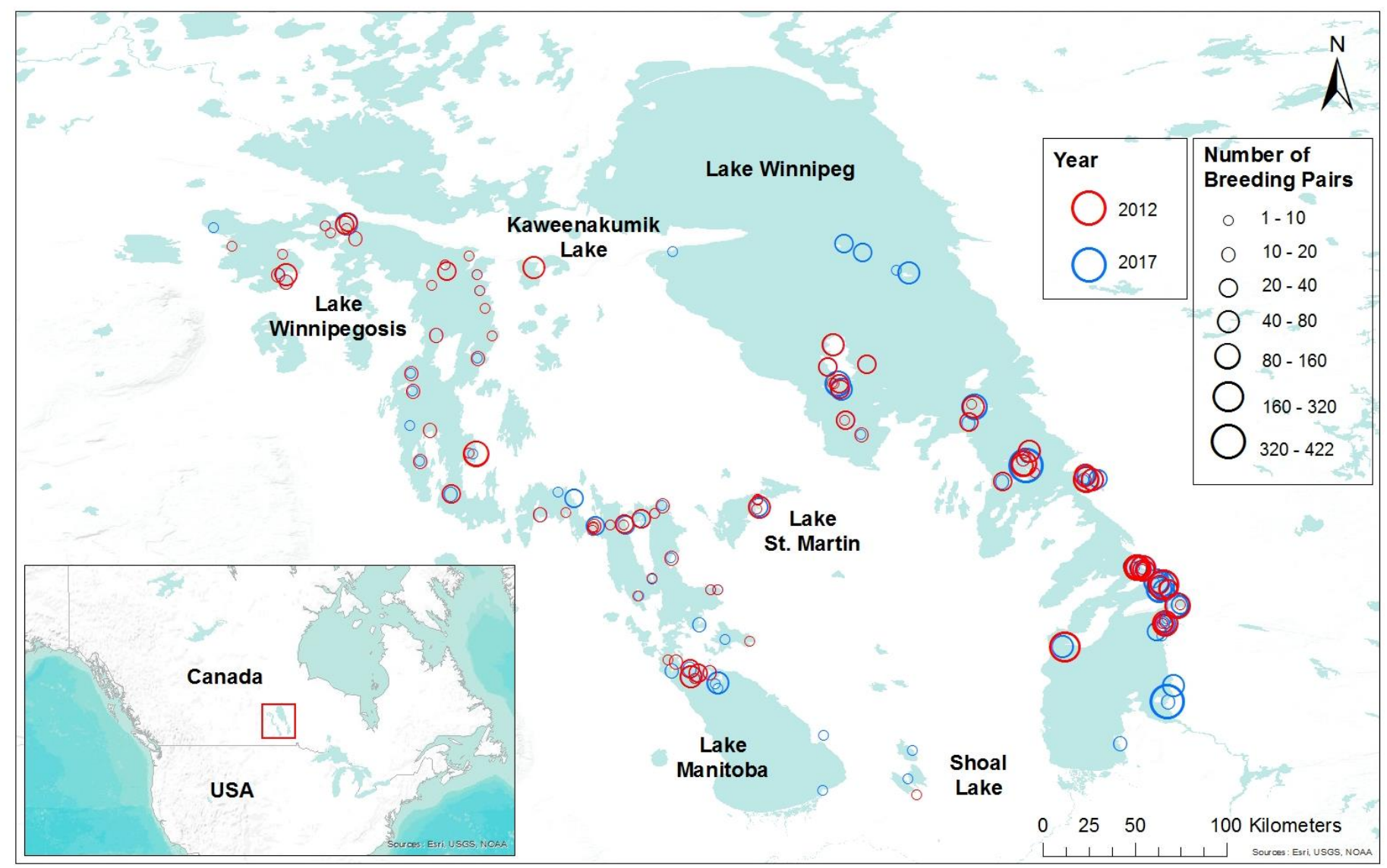

Figure A2.2. Number of breeding pairs of Herring Gulls on the large lakes of southern Manitoba based on aerial surveys conducted in 2012 and 2017. 


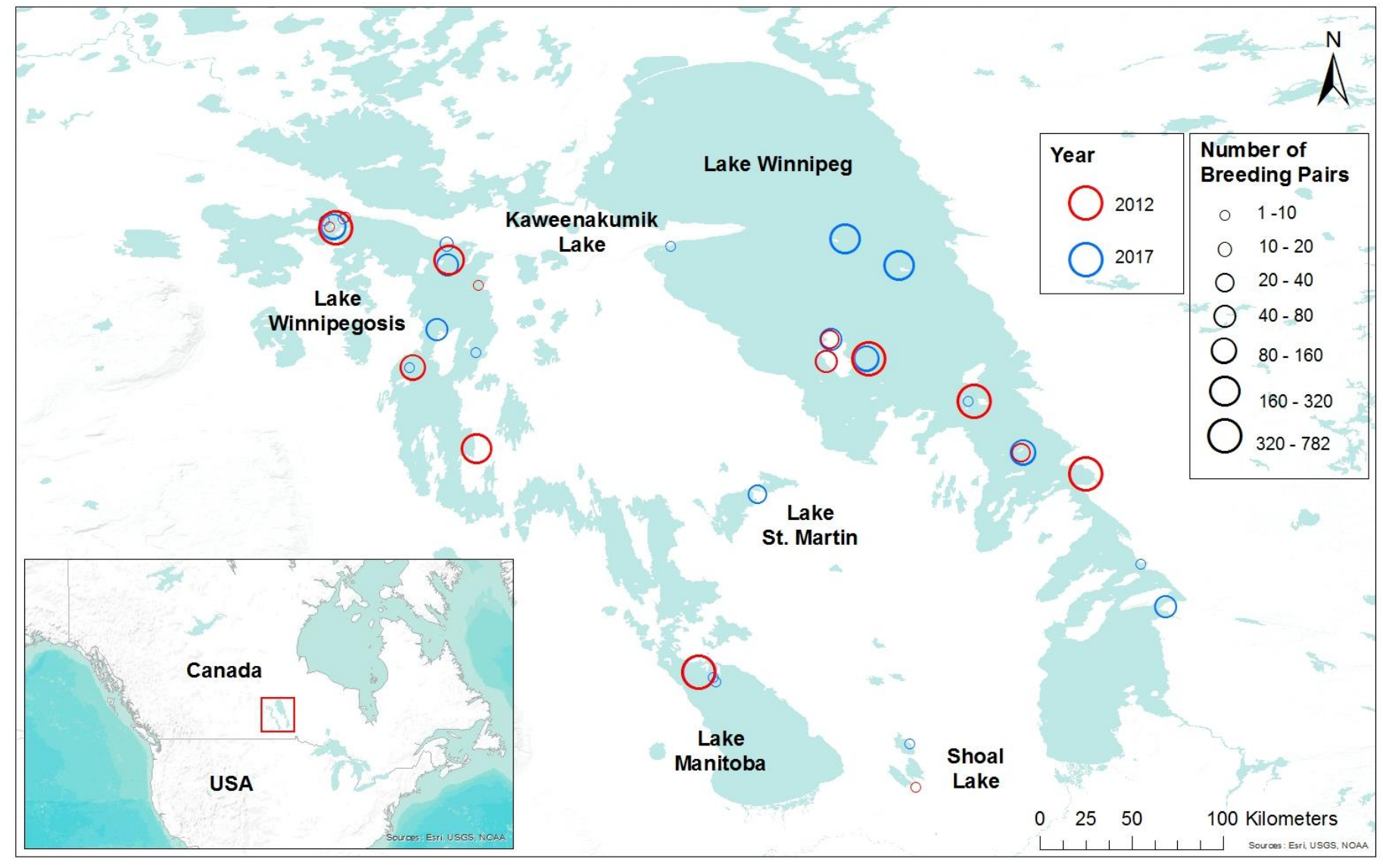

Figure A2.3. Number of breeding pairs of Caspian Terns on the large lakes of southern Manitoba based on aerial surveys conducted in 2012 and 2017. 


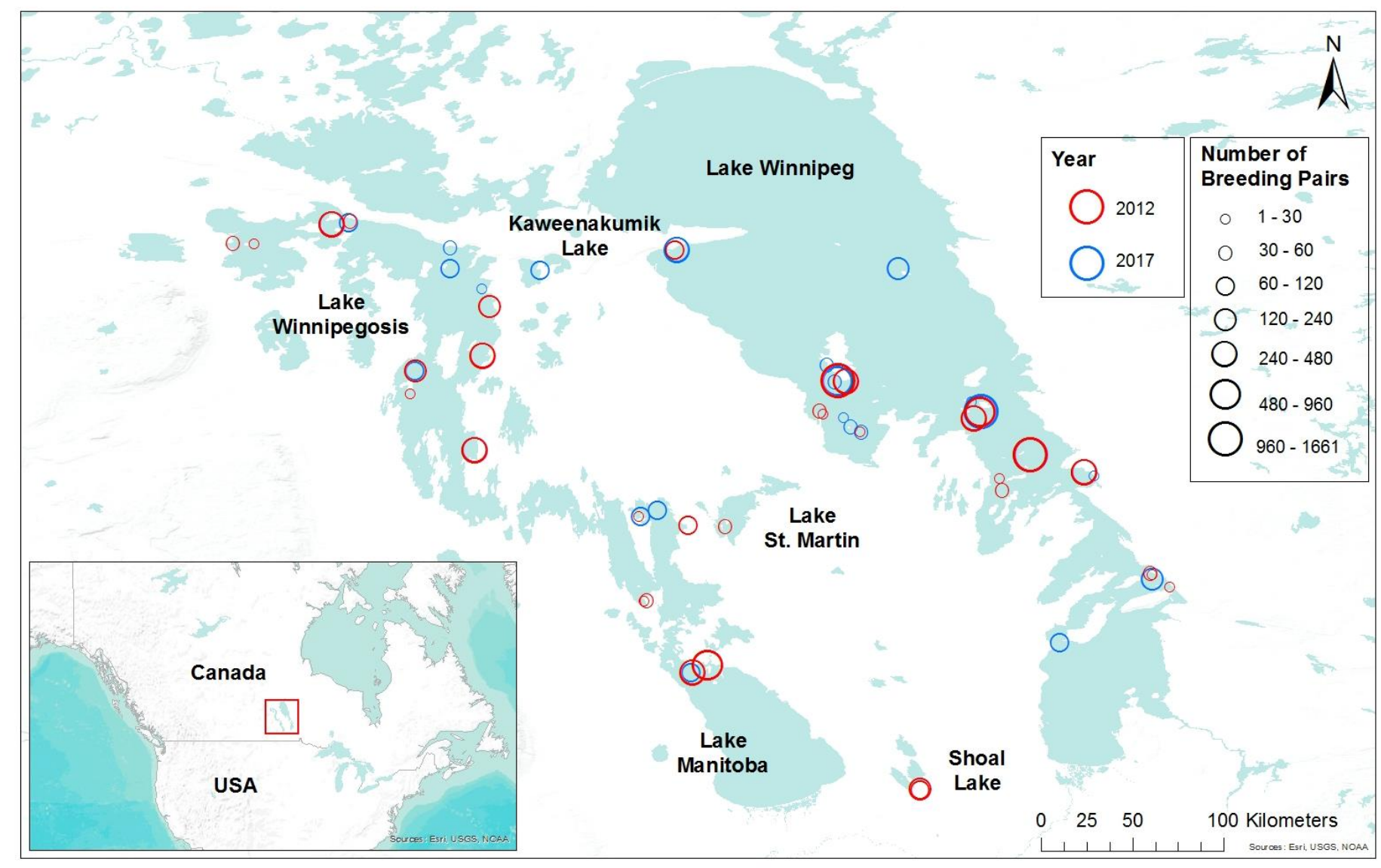

Figure A2.4. Number of breeding pairs of Common Terns on the large lakes of southern Manitoba based on aerial surveys conducted in 2012 and 2017. 


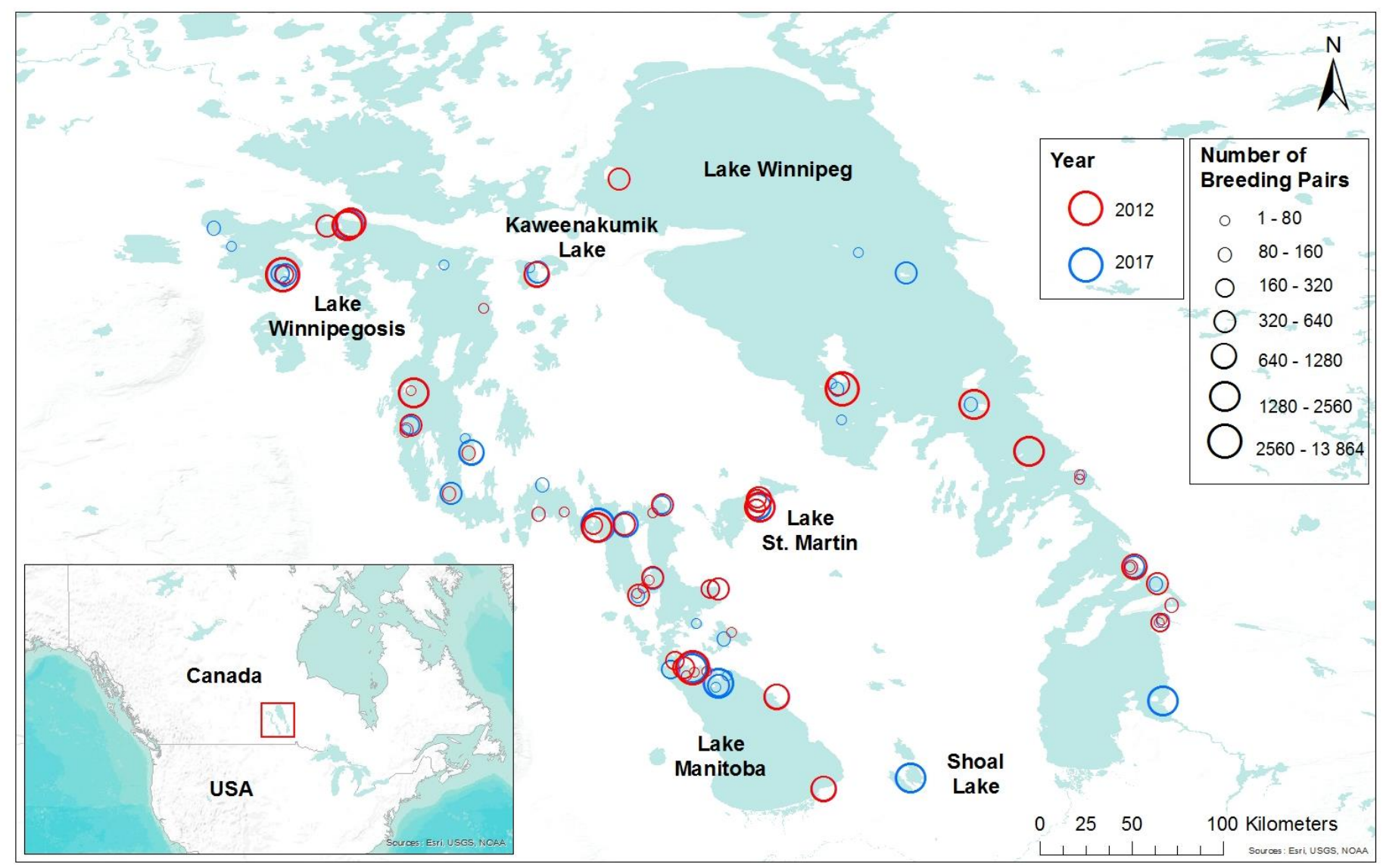

Figure A2.5. Number of breeding pairs of Double-crested Cormorants on the large lakes of southern Manitoba based on aerial surveys conducted in 2012 and 2017. 


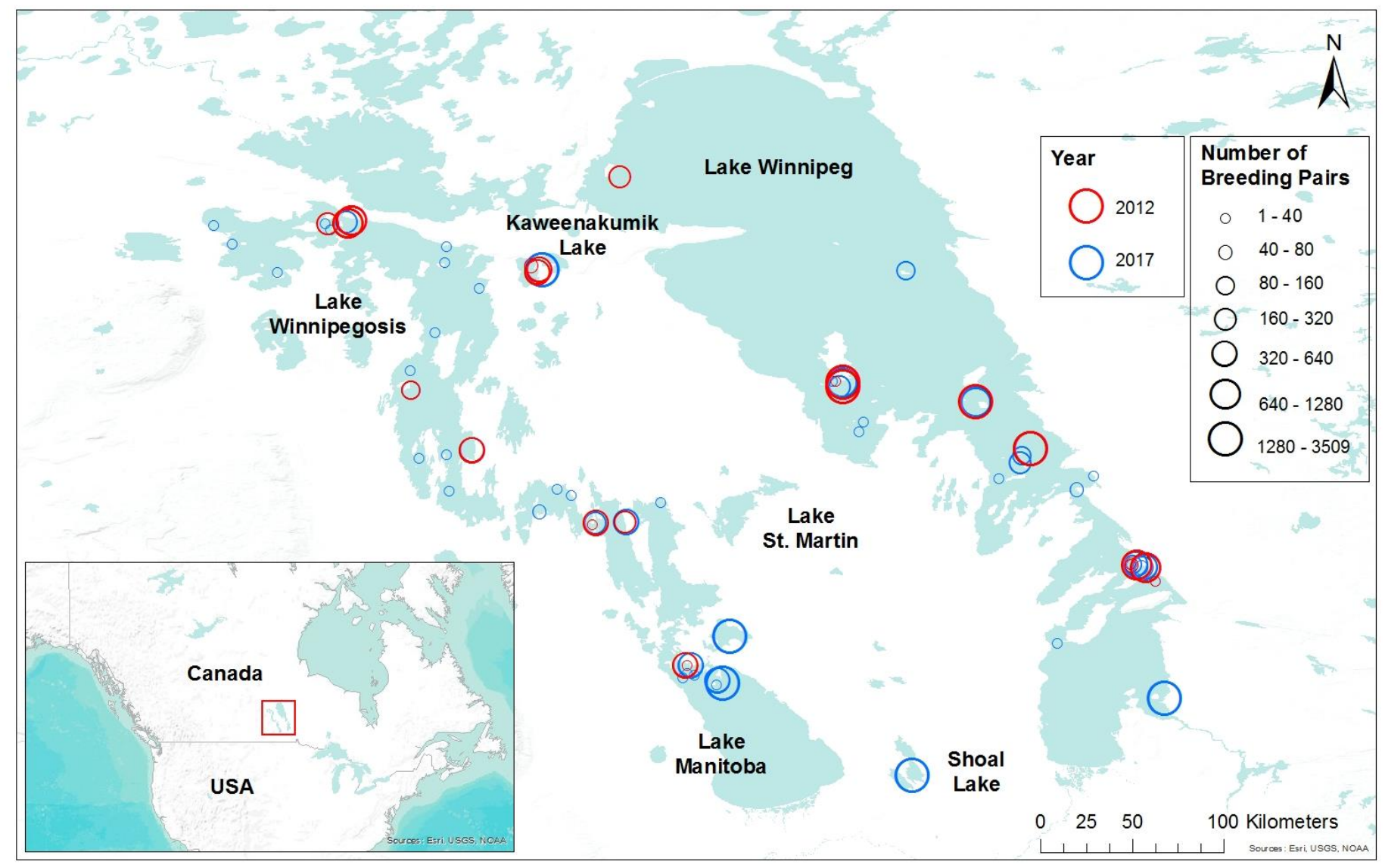

Figure A2.6. Number of breeding pairs of American White Pelicans on the large lakes of southern Manitoba based on aerial surveys conducted in 2012 and 2017. 
Appendix 3. Comparison of 2011, 2012, and 2017 colonial waterbird survey results from a portion of the large lakes of southern Manitoba, Canada.

Table 3.1. Numbers of breeding pairs, with number of colonies in brackets, during surveys at a subset of 23 potential colony locations on lakes Winnipeg, Winnipegosis, Kaweenakumik, and St. Martin, and Dog lakes.

\begin{tabular}{cccc}
\hline \hline & 2011 & 2012 & 2017 \\
\hline Ring-billed Gull & $254(7)$ & $11,238(15)$ & $3,557(12)$ \\
Herring Gull & $97(4)$ & $830(21)$ & $462(12)$ \\
Caspian Tern & $137(4)$ & $749(4)$ & $330(6)$ \\
Common Tern & $1,190(6)$ & $3,932(9)$ & $2,404(6)$ \\
Double-crested Cormorant & $797(5)$ & $2,824(6)$ & $3,106(7)$ \\
American White Pelican & $82(2)$ & $2,169(6)$ & $1,388(6)$ \\
\hline
\end{tabular}

